\title{
Group farming for sustainable aquaculture
}

\author{
Krishna Srinath*, Manpal Sridhar, P.N.R. Kartha, \\ A.N. Mohanan
}

\author{
Central Marine Fisheries Research Institute, Cochin 682 014, India
}

\begin{abstract}
Sustainable farming is a critical issue in aquaculture development. The concept is well understood but the issue is that of methodology for implementing it. It is well recognized that fragmented holdings have been a major constraint in the implementation of farming practices by small-scale farmers. In India 80 per cent of the shrimp production comes from small and marginal holdings which follow different systems of production, including the traditional 'pokkali' farms of Kerala state, improved traditional farming, and scientific methods. Group farming, which was highly successful in paddy farming, was tested among small-scale shrimp farmers practicing paddy and shrimp farming in rotation in a cluster of 'pokkali' fields in Kerala. The model served as an effective extension intervention to educate farmers on sustainability while helping them to improve their farming practices. The farmers, including women, could be equipped with the technology for farming not only shrimp but also finfish, crab and aquaculture feed production by strengthening the farmer-extensionist-researcher-political-administrative linkages. The work was done during 1993-1996 at the Central Marine Fisheries Research Institute, Cochin, India. The study formed a part of the action research project on empowerment of rural communities through extension. (C) 2000 Elsevier Science Ltd. All rights reserved.
\end{abstract}

\section{Introduction}

Aquaculture, mainly referring to the farming of fish and shellfish, forms a major enterprise in the primary production sector in the inland, freshwater brackishwater areas of India. Use of indigenous and foreign technologies has been in vogue in

\footnotetext{
* Corresponding author. Present address: Division of Extension, Information \& Statistics, Central Institute of Fisheries Technology, (Indian Council of Agricultural Research), Matsyapuri, P.O. Cochin 682029, India. Tel.: + 91-484-666845; fax: + 91-484-668212.

E-mail address: srinathm@satyam.net.in (Krishna Srinath).
} 
enhancing aquaculture production. As in the case of agriculture, small holdings account for 80 per cent of the production in shrimp aquaculture in the country. Since the advent of technologies for selective farming of shrimp species which offer high returns, traditional farmers have shown interest in implementation these methods in their farms. But several socioeconomic factors hinder the application of new methods. The most important among the constraints are fragmented holdings and poor socioeconomic conditions of small farmers for whom the aquaculture is a livelihood activity, the level of adoption of improved practices has been very low among them $[1,2]$. The potential of aquaculture to meet the challenges of food security and to generate employment and foreign exchange is clearly demonstrated by the rapid expansion of this sector with a higher annual growth rate when compared to that of livestock. If aquaculture is to develop and provide for current and future needs in a sustainable manner, establishing an enabling environment is the first step. Increasing the efficiency of resource use and productivity in general at the farm level and promoting responsible aquaculture should be the main objectives of development efforts. This is the joint responsibility of the government, technologists, social scientists and NGOs. Considering the significance of collective action in sustainable development the formation of farmers group must be promoted [3].

Group action in the transfer of agricultural practices has proven beneficial in overcoming many of the farming constraints. Group farming approach, which relies on synchronized farming operations and collective management by the farmers of a locality, is found to help them increase production by improving their access to the required inputs and reducing the cost of cultivation as indicated by studies carried out in rice farming in Kerala [4,5].

People benefit most from working collectively to protect and manage their resources. Farmers' groups provide an interface between the research and extension mandates and helps to understand the production and living conditions of the farmers, to strengthen their accountability, and to generate farming system-specific practices. Working with such an organization increases the effectiveness of extension workers as well as research workers and makes scientific information available to the small farmer whose ability to seek information might be undeveloped [6]. Impoverishment has been identified as the root cause for environmental degradation. Sustainable strategies should pay attention to land use practices, debt relief and environmental promotion and should involve sound economics and environmental accounting and assessment as well as use of operational guidelines. The impact of a particular technology depends on its nature, the size of the population deploying it, and the population's level of affluence. The need for community involvement in conservation and management is well established. In the past, neglecting community involvement has resulted in misunderstanding of the concepts. Community awareness and education are very important elements of sustainability [7]. Fish culture in small water bodies has received little research and extension support and the operations largely rely on farmer's experience and intuition. It is important to implement specific recommendations to reduce variations in management [8]. The above situation generally prevails in most of the small farms in India. Though a great deal of information is available with research and development agencies the effort to 
converge the inputs to the shrimp farms are limited. The issue being that of a methodology it was felt necessary that some models such as group farming that have proven success in agriculture be used as an intervention to educate the farmers on the improved practices and help them implement the same.

With a view to testing the usefulness of group farming approach in aquaculture, a study was carried out for the first time in 1993 among small and marginal farmers practicing shrimp aquaculture in the coastal village of South Chellanam near Cochin, Ernakulam in the district of Kerala, India and the findings are reported here.

\section{Objectives of the study}

Sustainable aquaculture is defined as the balanced use of resources and the ecosystem to satisfy human needs, conserve rural resources, and maintain and enhance the quality of the environment [9]. This study was an effort to use group farming as an intervention to help achieve the above aim. The specific objectives of the study were:

1. To formulate a specific model for group farming in shrimp aquaculture in paddycum-prawn culture ('pokkali') fields involving improved practices.

2. To demonstrate the model among a selected group of small and marginal farmers.

3. To utilize the infrastructure available for paddy farming in the implementation of improved shrimp farming practices.

4. To evaluate the effectiveness of the model in improving the incomes of farmers.

5. To assess the social gains brought about by the group approach.

6. To examine the changes in the ecological aspects of the selected geographical area.

7. To use the group farming strategy as an intervention for educating the farmers on sustainability.

8. To empower the farming community, particularly women, by directly involving them in farming and farm management activities, increasing employment opportunities, and reducing drudgery.

\section{Methodology}

\subsection{Selection of farmers}

In Kerala, the system of paddy-cum-prawn farming is traditionally practiced in brackish water farms known as 'pokkali fields', which usually cluster in contiguous geographical areas called 'padasekharams'. The saline-resistant 'pokkali' paddy (rice) and shrimp are farmed in rotation in these fields. The 'padasekharam' approach introduced by the Agricultural Department of the State aimed primarily at improving the paddy production through the collective implementation and management of farming practices. There are five such 'padasekharam' in the coastal village of Chellanam in the suburbs of Cochin. These clusters together cover a total area of about 500 ha. The clusters are further divided into 'blocks'. Block 'A' of the South Chellanam 'padasekharam', with an area of about 50 ha operated by 50 farmers, was 


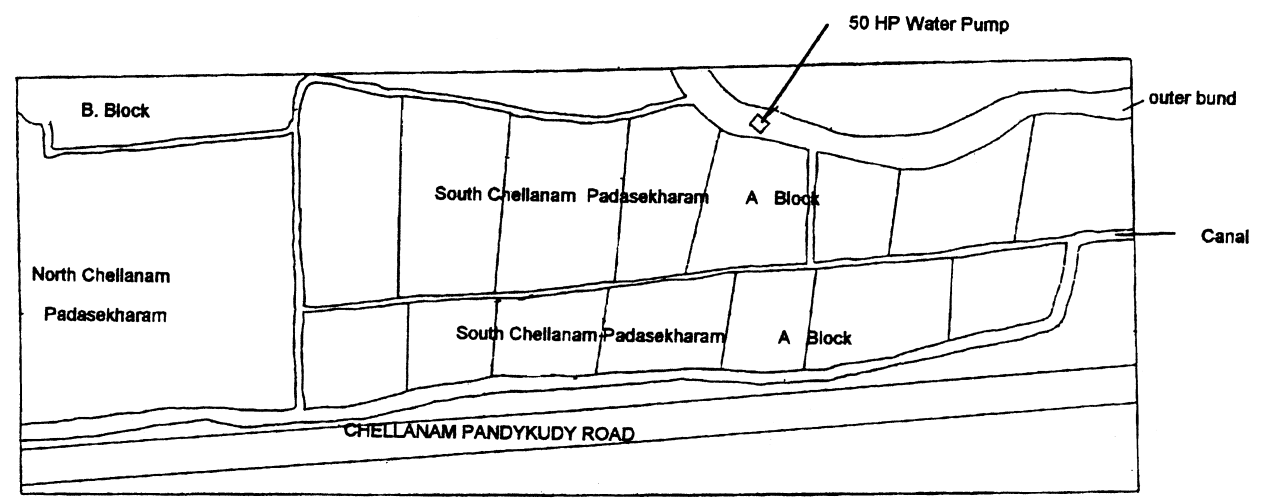

Fig. 1. Sketch showing the layout of the 'padasekharam' where the study was carried out.

selected for the study as they faced more farming constraints when compared to the other four clusters. The geographical layout of the selected area is given in Fig. 1.

\section{Preparatory phase}

Being the pioneering attempt in group farming in aquaculture, the first step was initiated to explain its contextual relevance to the farmer. The two years of preparatory work consisted of the following activities:

(i) Studying the shrimp farming practices followed by the farmers and the constraints involved in their implementation, which brought out several operational difficulties faced by the farmers [2].

(ii) Completing a pilot study on the shrimp farmers' perceptions of the group farming approach which produced a favourable response [10]

(iii) Delivering a village level seminar involving the research and development agencies in shrimp farming which was attended by a large number of farmers, including women.

(iv) Setting up two demonstration farms in the farmers' field with the participation of women.

\section{Implementation phase}

The implementation phase consisted of the following extension procedures:

\subsection{Resource assessment}

To form an idea about the layout of the 'padasekharam' - its water resources, crops grown, farming enterprises, the types of houses and people living in the area the 
design and layout of individual farms and identify the technological needs, a rapid assessment was carried out through a geographical transect and a physical map of the area was prepared. This was followed by discussions with groups of farmers located in different areas of the village to gain an understanding of the farming situation and develop a suitable action plan for group farming.

\subsection{Organizing the selected farmers}

Though the farmers were organized under the 'padasekharam' society for paddy farming, there was no organization in the selected area to propagate shrimp farming. This was due to the fact that the farmers in the 'padasekharams' engaged directly in paddy farming in their own fields but some of them leased their fields to other farmers or entrepreneurs for farming. This made it necessary to have a separate organization for farmers to implement the group farming programme. Shrimp farmers operating in the 'padasekharam' were identified and a new group farming society, named 'Cherukida Chemmeen Kottukrushi Sangham' (group farming society for small shrimp farmers) was formed and registered as a charitable society. The main responsibility of the Society was to plan and implement the group farming programme facilitated by the technical team, which consisted of extension specialists and shrimp farming technologists from the Central Marine Fisheries Research Institute. An executive committee to coordinate the farming operations was elected from members of the society.

\subsection{Training of farmers}

Training programmes of one-week duration in the improved shrimp farming methods were organized in the village, and in small groups, all the participating farmers were given detailed training in different aspects of shrimp farming. A special 15-day training programme was also conducted for 50 women belonging to the shrimp farmers' households. The Krishi Vigyan Kendra (the farm science centre of CMFRI), Brackish Water Fish Farmers' Development Agency, and the Kerala State Women's Development Corporation were the agencies associated with the training programmes for technical know-how and finance. Besides imparting training in shrimp farming, farmers were also told about aquaculture technologies for finfish, including ornamental fish and crabs.

\subsection{Development of a package of practices}

The quality of the water and soil in the fields was tested in the laboratory and farming practices were developed, taking into consideration the conditions available in each farm such as water and soil salinity, $\mathrm{pH}$, depth of water, access to feeder canals, availability of inputs, farming experience and above all the affordability for the farmer. The programme was confined to the summer season so that farmers could continue with their traditional practice of cultivating 'pokkali' paddy during monsoon. 


\subsection{Calendar of operations}

A schedule for implementing each of the farming operations, starting from field preparations and ending with harvest was prepared and distributed among the farmers. The schedule was prepared with enough flexibility to allow farmers to implement each step depending on the availability of inputs.

\subsection{Farm records}

The farmers were supplied with notebooks to record their day-to-day farming operations and the details of related expenditures and returns. This served as a means of training them in record keeping and formed the basis for validating the gains and losses due to the group farming approach.

\subsection{Method demonstration}

Two farms representing the general conditions in the selected area were identified for demonstrating different steps in farming such as field preparation; eradication; selection of seed; acclimatization, feeding; monitoring of farm conditions including growth, water quality and disease; and improved management measures. At each step of implementation in the model farms, the members of the group were provided with opportunities to observe and understand the new methods and repeat them in their farms. The demonstration also served as a reference for the comparison of the results of the other farmers.

\subsection{Farm and home visits}

The technical team and the executive committee of the group farming society visited each farm once a fortnight, monitored the progress, and provided technical advice to each farmer based on the specific conditions of his/her farm. The home visits helped to create rapport with farmers, involve the whole family in the programme and facilitate communication among them.

\subsection{Farmers' discussion groups}

Besides individual farm visits by the extension experts and the technologists, group meetings were conducted once a fortnight to review the progress of the group farming programme, share experiences and knowledge, clarify doubts, and suggest solutions to farming problems. Table 1 gives the details of extension contacts made under the programme.

\subsection{Contact with development agencies}

Meetings of the farmers and the extension team with development agencies concerned with inputs, subsidies and loans for shrimp farming were arranged to create awareness among farmers about the development schemes. 
Table 1

Number of extension contacts made with the farmers

\begin{tabular}{lc}
\hline Method & Number of contacts \\
\hline Home call & 10 \\
Farm visit & 8 \\
Group discussion & 12 \\
Training programme & 3 \\
Demonstration & 4 \\
Seminar & 2 \\
Handout & 2 \\
Circular letter & 12 \\
Lecture & 10 \\
Audio-visual aids & In the above contacts as required \\
\hline
\end{tabular}

\subsection{Employment generation for women}

Under the state government scheme for women's self-employment (Kerala State Women's Development Corporation), 10 women in the selected area were provided financial assistance and technical guidance to take up shrimp farming in their family farms. An all-women small-scale industry unit with the participation of five members was also set up as a part of the group farming programme for the onfarm production of CMFRI developed Mahima Shrimp Feed.

\section{Evaluation of the programme}

The gains of group farming were evaluated based on farmers' rating on success criteria including (1) attainment of group farming objectives (2) participatory features, and (3) the likely impact of the programme on the community. The overall success was assessed based on farmers' own ratings on the above aspects in general and was collectively reflected as percentage of success. Further, each criterion was evaluated separately using a three-point rating scale (high, medium and low) scored by each farmer in an interview schedule, as given below:

1. Attainment of group farming objectives was measured using farmers' ratings on expcetations and attainment of different objectives including increase in production, increase in income, reduction in farming cost, gain in technical knowledge, gain in financial assistance, implementation of scientific farming practices, organized marketing, better social status, leadership development, entrepreunership development, level of participation in group farming activities, solutions to social problems, mutual help and cooperation among farmers, and implementation of planned farming operations.

Chi-square analysis was carried out to test the departure of the farmer's expected rating of the objectives from that of the actual fulfillment. The results are presented as the percentage of farmers indicating the score under each criterion. 
2. Success on participatory features was rated on effectiveness of organization of group farming programme, participation of farmers including women and weaker farmers, freedom of expression, homogeneity of the group, achievement of collective decision, group cohesion and problem-solving efficiency.

3. The domains on which the group farming programme was likely to have an impact as presented to the farmers for rating consisted of family structure, family relations, fellow farmer relations, land transaction and land use, ecological improvement, infrastructure development, future perceptions about shrimp farming, role of women, political influence, farmers' contacts outside the village, risk taking willingness and linkage development with input agencies.

\section{Profile of the farmers}

A total number of 50 farmers operating in a area of about 50 ha participated in the group farming programme. They were in the age group of 30-65 yr, with 70 per cent of them falling between the age of 32 and 45. Fifty per cent of them had high school education. The individual farm size varied from 0.25 to 1.5 ha and only four farmers had bigger holdings extending up to 3 ha. Traditional filtration was followed in these farms on a small scale. Some of the farmers had attempted supplementary stocking but none of them had tried eradication. Wet feed such as clam meat was the supplementary feed most widely used by them. Farmers had paid little attention to field preparation or water quality management.

\section{Gains of group farming}

The gains of group farming - as indicated by the degree of overall success rated by the farmers in terms of attainment of objectives, participatory features and social and environmental impact - are presented in Table 2. The significant improvement in the farmers' perceived fulfillment of the objectives against the expected ratings of the objectives is taken as the success of the group farming concept.

Out of a total of 50 farmers who participated in group farming, 80 per cent reported that their expectations were fulfilled to a great extent, particularly in increasing production and reducing the cost of farming. Though the objective of gain in technical

Table 2

Gains of group farming - an overall assessment

Gains

Degree of success $(\%)$ collectively rated by farmers $(N=50)$ 
Table 3

Farmers' perception of attainment of group farming objectives ( $\%$ farmers) $(N=50)$

\begin{tabular}{|c|c|c|c|c|c|c|}
\hline \multirow[t]{2}{*}{ Objective } & \multicolumn{3}{|c|}{ Expectation } & \multicolumn{3}{|c|}{ Fulfillment } \\
\hline & High & Medium & Low & High & Medium & Low \\
\hline Increased production $^{\mathrm{a}}$ & 11 & 80 & 9 & 48 & 40 & 12 \\
\hline Increased income $\mathrm{b}^{\mathrm{b}}$ & 11 & 80 & 9 & 12 & 80 & 8 \\
\hline Reduction in farming cost $\mathrm{t}^{\mathrm{a}}$ & 22 & 69 & 9 & 48 & 48 & 4 \\
\hline Gain in technical knowledge ${ }^{a}$ & 36 & 46 & 18 & 62 & 34 & 4 \\
\hline Financial assistance $^{c}$ & 60 & 40 & - & - & - & - \\
\hline Implementation of scientific farming ${ }^{\mathfrak{c}}$ & 60 & 40 & - & - & - & - \\
\hline Organised marketing ${ }^{\mathrm{c}}$ & 9 & 9 & 82 & - & - & - \\
\hline Better social status ${ }^{\mathrm{b}}$ & 20 & 55 & 25 & 24 & 51 & 25 \\
\hline Leadership development $^{\mathrm{a}}$ & 0 & 73 & 27 & 12 & 44 & 44 \\
\hline Entrepreneurship development ${ }^{\mathrm{a}}$ & 0 & 73 & 27 & 16 & 44 & 40 \\
\hline Level of participation ${ }^{\mathrm{a}}$ & 18 & 64 & 18 & 36 & 56 & 8 \\
\hline Solving social problems $\mathrm{s}^{\mathrm{a}}$ & 18 & 73 & 9 & 32 & 68 & 0 \\
\hline Mutual help and cooperation ${ }^{\mathrm{b}}$ & 46 & 46 & 8 & 60 & 36 & 4 \\
\hline Planned farming operations ${ }^{\mathrm{a}}$ & 36 & 54 & 10 & 60 & 36 & 4 \\
\hline
\end{tabular}

${ }^{\mathrm{a}}$ significant $p<0.05$.

${ }^{\mathrm{b}} \mathrm{NS}$ not significant.

${ }^{\mathrm{c}}$ Not considered for analysis.

knowledge was fulfilled, it did not lead to the implementation of all the recommended practices by all the participating farmer, mainly due to economic constraints and indicated in Table 3. For example, recommended practices such as use of selected Penueus indicus seed either from wild collection or from hatchery, eradication of farms using mahua oil cake and periodical water exchange for water quality management in each farm individually by hiring pump sets could not be implemented by all the farmers due to the cost involved. The project also did not have any provision to meet this cost nor could any financial assistance be obtained under government scheme other than for training the farmers and credit support for women farmers.

Out of the 14 stated objectives (Table 3) there was significant departure in their fulfillment in the case of eight objectives realizing scores more than the expected. Among the remaining six there was no information on the three objectives namely, financial assistance, organised marketing and implementation of scientific prawn farming. For the other three objectives there was no significant departure between the level of expectation and the level of fulfillment as perceived by the farmers. Group farming as a social engineering model was found to be effective both by the farmers and the villagers in general.

\subsection{Economic and technological gains}

From the day notebooks kept by the 40 per cent of farmers who regularly maintained farm accounts and from their recollection of production estimates for the 
past three years, it was observed that 25 per cent of the farmers covered under the programme registered increased production owing to the implementation of some of the recommended practices and correction of past mistakes. According to them, this was the result of the variety of extension methods used to educate them on the technology. The farmers implemented the practice of eradication for the first time. The knowledge gained in the identification of shrimp species, supplementary feeding and water quality management have contributed to the success of farming. Depending upon the extent of implementation of recommended practices, farmers reported a two-to six-fold increase in the returns obtained. For example, a farmer who produced $30 \mathrm{~kg}$ in an acre of field in the previous years could obtain $75 \mathrm{~kg}$ with a little additional expenditure but with slightly more care in the use of inputs. Another farmer who used to get $50 \mathrm{~kg}$ in the previous seasons, could harvest about $300 \mathrm{~kg}$ shrimp by following most of the recommended practices. The estimated reduction of 20 per cent in farming costs could be brought about by taking collective effort in the following areas:

- Draining of fields for eradication using the pumping system installed for paddy farming vis-à-vis the cost of individually draining using hired pumps. A $50 \mathrm{Hp}$ water pumping system already available in the 'padasekharam' for paddy farming was used for draining and preparing the field.

- Procurement and transport of inputs such as eradication material and shrimp seed for farming.

- Travel for availing technical advice, training and testing of water and soil.

However, group farming objectives regarding financial support such as government loans and subsidies and organized marketing could not be achieved due to a lack of understanding of the government licensing procedures and farmers' indebtedness to the informal sources.

\section{Participatory features}

Under the present group farming programme that the farmers could plan their farming activities in advance in consultation with technical experts and fellow farmers. For the first time the farmers formed their own society and took collective decisions for the entire area. Eighty four per cent of the farmers felt that they had successfully participated in the group farming programme. It was an innovative extension intervention which provided new experience is assessing their farming situation and examining technology in the light of the conditions specific to their farms. They were satisfied with the organization and opportunity for participation, collective decisions and attention paid to economically weak farmers. Farmers also acknowledged that their relationship with their fellow farmers had improved and the participating farmers came forward to take up responsibilities related to group farming. Table 4 shows the farmers' perception on participatory features. 
Table 4

Farmers' rating on participatory features of group farming

\begin{tabular}{lllr}
\hline Feature & \multicolumn{2}{l}{$\%$ farmers rating $N=50$} \\
\cline { 2 - 4 } & High & Medium & Low \\
\hline Effectively organised & 76 & 17 & 7 \\
Successfully participated & 44 & 40 & 16 \\
Equal participation & 80 & 16 & 4 \\
Participation of women & 70 & 30 & - \\
Upliftment of economically weak farmers & 68 & 20 & 4 \\
Freedom of expression & 88 & 8 & 4 \\
Homogeneity & 86 & 10 & 4 \\
Collective decision & 88 & 8 & - \\
Group cohesion & 88 & 12 & - \\
Problem solving efficiency & 73 & 27 & \\
\hline
\end{tabular}

\section{Involvement of women}

One of the remarkable features of group farming according to the participating farmers and the public was the efforts made to attract women towards gainful employment activities related to shrimp farming. For the first time women directly participated in aquaculture, an area entirely dominated by men. Similarly, it was also for the first time that production of scientifically developed shrimp feed was taken up by women on a commercial basis (Table 5).

\section{Conflict resolution}

Conflict between shrimp farmers and the fishing labourers was a serious problem in the promotion of improved shrimp farming methods in the study locale. The labourers demanded $50 \%$ of the total harvest as their wages as practiced in the traditional filtration involving low investment where after periodical harvest and stocking by the farmer the field was left open for the labourers. This wage system was not suitable for farmers following improved farming methods consisting of selective one-time stocking of shrimp seed and other scientific management practices involving higher farming investments. This led to clashes and conflict between the two groups and resulted in poaching of the standing crop and economic losses to the farmer. Through repeated discussions and collective bargaining between the farmers and labourers, the wage ratio was lowered to 25 per cent and the conflict was resolved to some extent. No instance of inter-group conflict was reported during group farming period.

\section{Development of linkages}

Besides the involvement of extension specialists and shrimp farming technologists from the CMFRI, a number of development agencies were associated with the 
Table 5

Farmer's rating on possible impact of group farming ( $\%$ farmers $)(N=50)$

\begin{tabular}{lrcr}
\hline Domain & High & Medium & Low \\
\hline Family structure & 2 & 2 & 96 \\
Family relationship & 16 & 68 & 16 \\
Neighbourhood relationship & 18 & 56 & 16 \\
Fellow farmer relationship & 30 & 68 & 2 \\
Land transactions and land use & 100 & - & - \\
Ecological improvement & 100 & - & - \\
Infrastructure development & 100 & 20 & 4 \\
Future perceptions about farming & 72 & 12 & 4 \\
Role of women & 84 & 44 & - \\
Political influence & 52 & 33 & 4 \\
Farmers outside contact & 67 & 56 & - \\
Risk taking willingness & 40 & - & \\
Linkage development & 100 & & \\
\hline
\end{tabular}

programme at different stages. These included State Fisheries Department, Brackishwater Fishfarmers' Development Agency, Agency for Aquaculture Development in Kerala, Kerala State Women's Development Corporation, Kerala Agricultural University, Ernakulam District Administration and Chellanam Panchayat at the state level, the Marine Products Export Development Authority, National Bank for Agriculture and Rural Development, Central Institute of Brackishwater Aquaculture and Central Institute of Fisheries Technology at the national level as well as NGO's such as the local fishermen organizations, the church, and the media. The above linkages helped in creating awareness, training the farmers, setting up the shrimp feed production unit, providing loans and subsidies to women farmers, and securing public cooperation and political support. A similar outcome is reported from Bangladesh [11] in the empowerment of women farmers by developing interaction between farmers and researchers in a low input aquaculture system.

Although sufficient funding support could not be obtained in the form of credit and subsidies by associating with the development agencies in the programme, they could be sensitized towards the needs of the shrimp farmers.

\section{Sustainability features}

The tendency of 'pokkali' farmers to give up paddy farming and to completely switch over to much more remunerative shrimp farming is considered by the fisheries ecologists to be detrimental to the farming system.

The intervention through group farming helped in creating awareness among the farmers about the need to restrict shrimp farming to the summer season and to continue the traditional practice of paddy farming during the monsoon. Previously, the farmers had the tendency to switch over to shrimp farming which was economically 
more profitable, but not ecologically sound. It is detriment if some farmers sowed paddy and other stocked shrimp in their farms lying in the same cluster due to the incursion of saline water, hence it was necessary for sustainability to bring uniformity in the farming pattern. Moreover, since the perennial shrimp farms held saline water throughout the year, the houses situated among the fields were damaged due to water logging. This problem was brought to the notice of the government authorities and in the next year the local revenue divisional office banned shrimp farming in the South Chellanam during the monsoon season, i.e., June-October. Consequently, the paddy farmers' society decided not to let saline water into the farms until the month of October when the paddy would be harvested and shrimp farming operations begun. This was one of the important sustainability messages the group farming programme could drive home.

The technologies have economic and ecological dimensions and to be sustainable, they must be location specific. Sustainable shrimp farming calls for participatory action in planning the farming operations, protection of the ecosystem by the implementation of appropriate farming technology and supporting traditional activities which form the livelihood of those who are not doing shrimp farming. The group farming programme has attempted to develop an action agenda to ensure harmony, implementation of regulations, and development of a sustainable land use system.

\section{Attainment of research objectives of the study}

Evaluation of the study with reference to its research objectives is summarized in Table 6 .

\section{Conclusion}

National aquaculture plans, wherever they existed, were mainly directed at establishing and strengthening aquaculture through cost-effective production and marketing techniques. The environmental impact became a matter of concern only with the intensification of techniques, and solutions to problems were sought only when disaster occurred. Planning is required not only at national level but also at farm-based micro level [12]. A similar situation developed in shrimp aquaculture in India. While small farmers were trying to catch up with modern farming techniques, intensive shrimp production in a few sites was getting closed due to disease outbreak. Big investors who met with losses in the aquaculture industry came in search of farms in traditional areas offering big prices. It was in this juncture that the group farming programme was introduced in the village. The timely intervention by the extension team to discourage small farmers from the unsustainable temptations seems to have paid good dividends to the farmers of Chellanam. 
Table 6

Achievement of research objectives

Objective

Achievement

Formulation of a model for group farming for

Formulated a location-specific group farming model shrimp aquaculture in the paddy-cum-shrimp farms consisting of package of practices and procedure for implementation

Demonstration of the model among selected group of small and marginal farmers

Utilising the farm infrastructure and development programmes for rice farming for implementing improved practices

Achieving social and economic gains

Implemented the group farming model in a typical paddy-cum-shrimp farming system

The water pumping system for paddy farming available in the 'padasekharam' was effectively used for field preparation in shrimp farming

Increase in income, reduction in farming costs, farmers participation in linkage development were achieved

Improving ecological aspects and sustainability

With village, district, state and national level government agencies and local NGOs implemented farming practice suitable for each farm, continuation of the traditional system of rotating paddy and shrimp and restricting shrimp farming to a particular season

Empowering farmers, particularly women, with improved farming practices

Training of farmers in shrimp farming and other useful technologies, involving women directly in shrimp farming, setting up of small-scale production unit by women for ecofriendly shrimp feed which helped in their empowerment

\section{Acknowledgements}

The authors express their gratitude to Dr. P.V. Rao, former Director, CMFRI and Dr. M. Devaraj, present Director, CMFRI for the encouragement and support in conducting the study. Planning and implementation of group farming was a huge task, particularly the fortnightly visit to monitor 50 farms spread over 100 acres was physically very strenuous. The first author who was the project leader owes the success of the study to the whole hearted cooperation of the team members. The help rendered also by Mrs. K.P. Salini and Mr. N.K. Harshan, Technical Assistants, in extension work is gratefully acknowledged.

\section{References}

[1] Krishna S. Technology transfer for sustainable shrimp farming. Proceedings of Workshop on Technology Transfer for Sustainable Shrimp Farming. Madras: Central Institute of Brackishwater Aquaculture, 1995. p. 146-53.

[2] Krishna S. Adoption of shrimp culture practices by small farmers. Seafood Export Journal 1996;XXVII(10):9-12. 
[3] Barg U, Phillip J. Environmental sustainability. FAO Fisheries Circular, 886 1997;4(1):55-9.

[4] Hali R. Group farming for rice development in Kerala. Kerala: Department of Agriculture, 1998.

[5] Shobhana G, Shylaja S. Group farming, a potential approach to economic paddy production in Kerala - a case study. Journal of Extension Education 1994;4(1):817-920.

[6] Bebbington AJ. Farmers and community organisation in System oriented research in agriculture and rural development. Extension Digest 1994;III(3):1.

[7] Lonegran C. Impoverishment, population and environmental degradation. Environmental Conservation 1993;XX(4):328-34.

[8] FAO and NACA. Survey and analysis of aquaculture development. Research priorities and capacities in Asia. FAO Fisheries Circular, 930 (1997); 1-263.

[9] Folke C, Kautsky N. Aquaculture with its environment prospects for sustainability. Ocean and Coastal Management 1992;17(1):5-24.

[10] Rajeev P, Krishna S. Farmers' perception of group farming in prawn culture. Marine Fisheries Information Service 1995;137:8-11.

[11] Lightfoot C, Gupta MV, Ahmed M. Low external input sustainable aquaculture for Bangladesh-an operational frame work. Naga, ICLARM, 1992, p. 9-12.

[12] Pillai TVR. Aquaculture and the environment. Fishing news books. 1992. p. 116-62. 